\title{
NACHRUF AUF MILAN ŽITNÝ
}

\author{
ANNA FOSSE
}

Die Nachricht, dass doc. PhDr. Milan Žitný, CSc., geboren am 11. Januar 1948 in Krajné, ein führender slowakischer Skandinavist und Germanist, herausragender Übersetzer, respektierter, beliebter Pädagoge und in jeder Hinsicht geschätzter Mensch, uns am 16. April 2019 für immer verlassen hat, macht uns fassungslos. Nicht nur aufgrund seines unerwarteten Ablebens, sondern auch, weil wir uns unbewusst oft wünschen, dass die Menschen, die über Generationen hinweg zu fachlichen und persönlichen Vorbildern werden, möglichst lange unter uns bleiben und weil wir ihren Tod nicht wahrhaben wollen. Ein sterblicher Mensch, der ein unsterbliches Lebenswerk hinterlässt, erinnert uns an die Unversöhnlichkeit von Zeitlichkeit und Ewigkeit im Sinne Søren Kierkegaards, und dies umso mehr, als das Werk dieses Philosophen der slowakischen Leserschaft vor allem dank Žitný nähergebracht wurde. Nach dieser traurigen Nachricht dachten wir viel an seine Familie, die sein Tod am schmerzlichsten traf. Schließlich erzählte er uns oft davon, wie sehr er sich auf Augenblicke der Entspannung mit der Familie nach seiner Pensionierung gerade in diesem Jahr freute.

In Anbetracht seiner akademischen Tätigkeit, seiner Übersetzungs-, Rezensionsund Redaktionsarbeit scheint es, als wären ihm zu Lebzeiten nicht viele solcher ruhigen Augenblicke vergönnt gewesen. Der akademische Weg, für den er sich entschied, war kein einfacher. Er widmete sich unter anderem der Forschung zur slowakischen Rezeption nordischer AutorInnen, und seine beiden Monographien Nordische Literaturen in der slowakischen Kultur (2012) und Koordinaten der nordischen Literaturen (2013) bezeugen als Schlüsselwerke dieses Bestrebens wohl am besten, wie viel Geduld und beharrliche Arbeit solche Forschung erfordert. Im zentralen Bestandteil seiner akademischen Forschung beschäftigte sich Žitný mit der Hervorhebung des Kontextes von Entstehung und Rezeption verschiedener, nicht nur literarischer Schlüsselwerke. Ein lebhaftes Interesse charakterisierte seinen Beitrag zur zentraleuropäischen Bjørnson-Forschung - er war mit Abstand der bewandertste Kenner von Leben und Werk Bjørnstjerne Bjørnsons in der Slowakei.

Ebenso wird in der slowakischen Kultur der Name Milan Žitný immer mit der Übersetzung von Werken großer literarischer Persönlichkeiten verbunden bleiben, darunter Franz Kafka, August Strindberg, Henrik Ibsen, Hans Christian Andersen und Ingmar Bergman, ebenso wie von anspruchsvollen philosophischen Werken - außer Kierkegaard gehören in diese beachtliche Liste Dilthey, Goethe und Habermas. Dank dieser Texte war Žitný als Übersetzer und Autor großartiger Nachworte, in denen er mit der ihm eige- 
nen Leichtigkeit und Eleganz die anspruchsvollsten Gedankengänge erläutert, auch der breiteren Öffentlichkeit mit einer Vorliebe für gute Bücher ein Name. Diejenigen unter uns, die die Ehre hatten, unter seiner Betreuung ihre Dissertation zu schreiben, erlebten oft einen Neid im positiven Sinne und während der Auslandsaufenthalte auch basses Erstaunen - das Spektrum und die Bandbreite von Žitnýs Kenntnissen und kulturellen Beiträgen weckten selbst unter führenden AkademikerInnen, insbesondere in den nordischen Ländern, regelmäßig großen Respekt.

Als im Jahr 2015 am Theaterinstitut in Bratislava eine Anthologie der nordischen Gegenwartsdramatik fertiggestellt wurde - Milan Žitný nahm als der Erfahrenste unter uns souverän die schwierigsten Übersetzungen auf sich und übersetzte als erster in der Slowakei einen Text aus dem Färöischen -, machten wir Witze darüber, dass, wenn ein färöischer Dramatiker vom Übersetzer Henrik Ibsens und August Strindbergs zu uns gebracht wird, auch das färöische Drama ein bisschen zu Weltruhm komme. Bei solchen Komplimenten - ob nun augenzwinkernd oder nicht - zeigte Milan stets nur ein bescheidenes Lächeln. Er stand nicht gerne im Mittelpunkt und setzte sich nicht in Szene; umso höher ist ihm anzurechnen, wie viel Anerkennung er der Arbeit von KollegInnen schenkte. Davon zeugt auch sein großer Anteil an der Entstehung des zweibändigen Lexikons slowakischer Übersetzerinnen und Übersetzer des 20. Jahrhunderts. Unter uns, der jungen Generation in Literaturwissenschaft und Übersetzung, stiftete er stets einen Sinn für Kollegialität und gegenseitiges Wohlwollen und war selbst ein hervorragendes Beispiel für solche Werte. Wir können nur dankbar sein, dass ein Mensch wie er während seines aktiven Berufslebens an verschiedenen Orten tätig war - am Institut für Weltliteratur der Slowakischen Akademie der Wissenschaften, an den pädagogischen Fakultäten in Bratislava und Trnava und seinerzeit auch am Institut für Slawistik an der Universität zu Köln.

Milan Žitný stand in vielerlei Hinsicht der philosophischen Form des Aphorismus nahe - nicht nur als Übersetzer, sondern auch als Mensch. Wenn es darauf ankam, wusste er seine Gedanken oder seine Einstellung prägnant und oft humorvoll zum Ausdruck zu bringen. In dem Essay Franz Kafka, Dichter des Unmöglichen, erschienen 2013, bezieht er sich auf einen beliebten Aphorismus, in dem Kafka bemerkt, dass die Kunst vor allem mit dem „von der Wahrheit Geblendet-Sein“ zu tun hat. Er zitiert auch aus Kafkas Korrespondenz: „Ein Buch muss die Axt sein für das gefrorene Meer in uns“, und ergänzt diesen Klassiker: „Ein Buch, bzw. Literatur sollte nichts Erzieherisches, Belehrendes sein, aber genausowenig etwas geistlos Unterhaltsames, sie sollte keine Ansammlung altkluger Vorschriften sein. Sie sollte etwas sein, das auch zu einem schmerzvollen Preis unser teilnahmsloses Gewissen wachrüttelt und es uns ermöglicht, uns all dessen bewusst zu werden, was irgendwo in den Tiefen der Seele verschwiegen, verheimlicht, hinter einem eisigen Panzer verdeckt ist."

Solchen Büchern weihte Milan Žitný sein Leben als Wissenschaftler, Übersetzer und Pädagoge. Und genau deshalb fand er wohl auch viel Sinn darin, einen so großen Teil seines Lebens mit Büchern zu verbringen, stets „tippend“ an seiner Schreibmaschine und später an seinem Computer. Im Nachwort zu seiner eigenen Übersetzung von Kierkegaards Tagebuch eines Verführers formulierte er seine Überzeugung, dass ein Impuls aus Kierkegaards Werk mit Gegenwartsrelevanz die Mahnung des Philosophen sei, für sich und sein Handeln Verantwortung zu übernehmen. Es besteht kein Zweifel daran, dass er mit dieser Interpretation der Botschaft recht hatte, und für diejenigen, die ihn kannten, 
besteht auch kein Zweifel daran, dass er sie selbst lebte. Dank Milan Žitný werden auch zukünftige Generationen Zugang zu großer Literatur und Philosophie haben und so mit einer Vielzahl an Texten in Kontakt kommen, die die Wahrheit gegenüber der Verlogenheit und die Verantwortung gegenüber der Gleichgültigkeit verteidigen. Milan Žitný gebühren dafür große Anerkennung und großer Dank.

Möge er in Frieden ruhen! 